\title{
Endothelial-to-Mesenchymal Transition as Underlying Mechanism for the Formation of Double-Chambered Right Ventricle
}

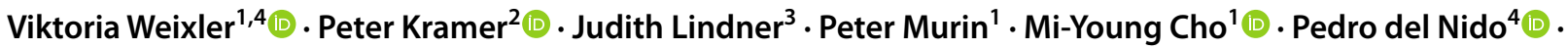 \\ Joachim Photiadis ${ }^{1}$ (D) $\cdot$ Ingeborg Friehs ${ }^{4}$ (i)
}

Received: 26 October 2021 / Accepted: 12 January 2022 / Published online: 27 January 2022

(c) The Author(s) 2022

\begin{abstract}
Double-chambered right ventricle (DCRV) is a progressive division of the right ventricular outflow tract (RVOT) often associated with a subaortic ventricular defect (VSD). The septation is caused by a mixture of hypertrophied muscle bundles and fibrous tissue, whereof the latter is of unclear pathogenesis. Our group has previously reported that flow disturbances lead to formation of fibroelastic tissue through a process called endothelial-to-mesenchymal transition (EndMT) but it is unclear whether the same mechanism exists in the RV. Tissue from patients undergoing repair of DCRV was examined to identify the histomorphological substrate of this tissue. Demographic and pre-/post-operative echocardiographic data were collected from nine patients undergoing surgery for DCRV. RVOTO tissue samples were histologically analyzed for myocardial hypertrophy, fibrosis, elastin content, and active EndMT (immunohistochemical double-staining for endothelial and mesenchymal markers and transcription factors Slug/Snail) and compared to four healthy controls. Indication for surgery were symptoms and progressive RVOT gradients. A highly turbulent flow jet through the RVOTO and VSD was observed in all patients with a preoperative median RVOT peak gradient of $77 \mathrm{mmHg}$ (IQR 55.0-91.5), improved to $6 \mathrm{mmHg}$ (IQR 4.5-17) postoperatively. Histological analysis revealed muscle and thick infiltratively growing fibroelastic tissue. EndMT was confirmed as underlying patho-mechanism of this fibroelastic tissue but the degree of myocardial hypertrophy was not different compared to controls $(P=0.08)$. This study shows for the first time that an invasive fibroelastic remodeling processes of the endocardium into the underlying myocardium through activation of EndMT contributes to the septation of the RVOT.
\end{abstract}

Keywords Endothelial-to-mesenchymal transition $\cdot$ Double-chambered right ventricle

$\begin{array}{ll}\text { Abbreviations } \\ \text { CD31 } & \text { Cluster of differentiation } 31 \\ \text { DCRV } & \text { Double-chambered right ventricle } \\ \text { EndMT } & \text { Endothelial-to-mesenchymal transition } \\ \text { H\&E } & \text { Hematoxylin and eosin } \\ \text { IQR } & \text { Interquartile range } \\ \text { MT } & \text { Masson's trichrome } \\ \text { PV } & \text { Pulmonary valve }\end{array}$

Ingeborg Friehs

ingeborg.friehs@childrens.harvard.edu

1 Department of Congenital Heart Surgery/Pediatric Heart Surgery, German Heart Center Berlin, Berlin, Germany

2 Department of Congenital Heart Disease/Pediatric Cardiology, German Heart Center Berlin, Berlin, Germany

3 Institute of Pathology, Charité, Berlin, Germany

4 Department of Cardiac Surgery, Harvard Medical School, Boston Children's Hospital, 300 Longwood Ave, Boston, MA 02115, USA
RV Right ventricle

RVOT/O Right ventricle outflow tract/obstruction

$\alpha$-SMA $\quad \alpha$-Smooth muscle actin

VSD Ventricular septal defect

\section{Introduction}

Double-chambered right ventricle (DCRV) is a rare congenital heart condition, found in less than $3 \%$ of all congenital heart defects and is detected in 1:36,000 autopsies [1]. First described in 1858 by Peacock as a mid-cavitary right ventricular outflow tract obstruction (RVOTO), it is defined as a progressive division of the right ventricle (RV) into two chambers, a high-pressure inlet- and a low-pressure outlet chamber [1-3]. A subaortic ventricular septal defect (VSD) is the most common associated anomaly occurring in $>90 \%$ of all patients [4]. 
Although the exact genesis of this pathological RV septation is still unknown, several mechanisms have been proposed including hypertrophy of the moderator band and/or hypertrophy of accessory septo-parietal trabeculations [1]. Since surgical correction is generally performed early in life, the natural history and progression of this disease have not been thoroughly investigated. Case reports describing the formation of DCRV in adult unoperated patients suggest an important contribution of hypertrophied anomalous muscle bundles becoming obstructive over time which suggests an acquired obstruction with an underlying congenital substrate $[2,4]$. Increasing intraventricular gradients measured over time in unoperated patients with DCRV support this hypothesis. Formation of two chambers within the RV, and the presence of a gradient across the RV cavity is indicative of DCRV.

Histological analyses of resected DCRV tissue describe a mixture of hypertrophied muscle bundles and fibrous tissue, whereof the latter is of unclear pathogenesis $[4,5]$. One hypothesis suggests that flow disturbances play a role in the development of this fibrotic tissue. Due to the septation within the RV, blood flow must pass within the RV either above the septation, between the septation and the tricuspid valve or through a narrow channel between the septation and the septal wall which causes significant turbulence. Furthermore, increased blood flow with high-pressure jet formation is present across the VSD [6]. It has also been reported that in some cases this high-pressure flow situation may lead to spontaneous closure of the VSD over time $[1,7]$. These findings indicate that the formation of DCRV is the pathophysiological result of flow disturbances rather than only hypertrophied muscle bundles that lead to the formation of DCRV.

Our group has previously reported that flow disturbances caused by jets due to valvar defects on the left side of the heart, lead to remodeling of the LV cavity through formation of fibroelastic tissue $[8,9]$. Furthermore, we established that the underlying patho-mechanism for the formation of this fibroelastic tissue is endothelial-to-mesenchymal-transition (EndMT) which serves as physiological process for valve and septal formation during fetal development $[10,11]$. It is, however, unclear whether the formation of fibroelastic tissue is also triggered by the same mechanism on the right side of the heart. With access to tissue resected from patients undergoing repair of DCRV, we sought to thoroughly describe the tissue histologically, and determine whether formation of fibroelastic tissue through activation of EndMT and not only hypertrophy of anomalous muscle bundles is associated with the septation of the RVOT into a two-chambered ventricle.

\section{Material and Methods}

\section{Ethics Statement}

The research protocol (EA2/152/19) was approved and the study conducted in accordance with the standards of the institutional ethics committee of the Charité Berlin, Germany. Patients diagnosed with DCRV scheduled to undergo surgery for RVOTO resection and/or their legal guardians were asked for consent prior to surgery and enrolled in this study. Unidentified RV histological slides from healthy hearts served as controls $(n=4)$.

\section{Patients}

Nine patients diagnosed with DCRV who underwent RVOTO resection at the German Heart Center Berlin between September 2019 and January 2021 were included in this study. Diagnosis, medical history, previous procedures/ interventions, clinical presentation prior to surgery, indication for surgery, intraoperative findings and imaging studies preoperatively and at last follow-up were recorded for all patients. During routine surgery, RVOTO tissue resected for correction of DCRV was obtained for further analysis. If a VSD was present, VSD closure with an autologous pericardial patch was performed.

\section{Echocardiographic Diagnosis and Assessment of Flow Disturbances}

All available pre- and postoperative echocardiograms were evaluated; and all patients had at least one pre- and one postoperative echocardiogram performed at our institution and three patients underwent additional imaging studies. VSD morphology (defect size and localization), shunt direction across the VSD, and pulmonary valve morphology were assessed. Additional parameters recorded on echocardiograms included peak velocities and derived pressure gradients across the VSD and across the RVOT/PV.

\section{Histological Analysis of Resected RVOT Tissue}

The resected tissue was stored in $10 \%$ neutral buffered formalin, embedded in paraffin and sectioned for staining and histological analysis. Tissue morphology and myocardial hypertrophy in DCRV and healthy control samples were determined by staining with hematoxylin and eosin (H\&E). The number of nuclei per field of vision was used to semiquantitatively determine the degree of myocardial hypertrophy through assessing the area of myocardium/nuclei per field of vision. Ten randomly selected fields from each slide 
( $n=9-$ RVOTO and $n=4-$ non-RVOTO) were taken, and analysis was performed with ImageJ (version 2.0.0-rc-43, National Institute of Health, Bethesda, MD, USA). Masson's trichrome (MT) staining served to visualize the degree of fibrosis, and Van Giessen elastin staining to determine the involvement of elastin deposition in the disease process. Methods of quantifying muscle tissue in histologic sections have previously been described in detail by our group [12].

Active EndMT was determined by immunohistochemical identification of endothelial cells double-stained with an endothelial marker, cluster of differentiation 31 (CD31; 1:100; Dako/Agilent, Santa Clara, CA, USA), and a mesenchymal marker, $\alpha$-smooth muscle actin ( $\alpha$-SMA; 1:100; Abcam, Cambridge, MA, USA), which is indicative of active EndMT as we have described in more detail previously [8]. In addition, all samples were stained for the transcription factors Slug/Snail (1:100; Abcam) to confirm active EndMT. Co-localization of Slug/Snail with nuclei of endothelial cells is considered affirmative of active EndMT. All slides were visualized using a Zeiss Axio Observer Z1 light microscope and fluorescence microscope (Carl Zeiss Microscopy, LLC, White Plains, NY) with a Nikon $20 \times$ objective (numerical aperture $=20 x / 0.45$, Nikon, Tokyo, Japan).

\section{Statistical Analysis}

Descriptive data are expressed as median and interquartile range (IQR) or frequency (\%). Quantitative data with normal distribution is reported as mean \pm standard deviation. Comparison of DCRV samples with non-RVOTO control samples was performed using $t$-test, $P \leq 0.05$ was considered statistically significant.

\section{Results}

\section{Patients}

A total of nine patients were included in this analysis and their baseline characteristics are summarized in Table 1. Male gender was dominant $(66.7 \% ; 6 / 9)$. Median age in the entire cohort was 0.8 (IQR $0.5-5.2$ ) years with almost half of the patients $(44.4 \%$; $4 / 9)$ beyond one year of age and one adult patients. Transcutaneous oxygen saturations were within normal ranges between 96 and $99 \%$ but one patient (patient \#2) displayed hypoxemia.

Diagnosis of DCRV was predominantly established in the neonatal period or shortly thereafter (90\%) and only in one patient (patient \#3) it was diagnosed at the age of fourteen. In this patient, a VSD which had been described before, had functionally closed spontaneously and was pinhole-sized at the time of surgery, thus, initially, a VSD was present in all patients. Additional cardiac malformations were present in four patients. Patient \#1 showed right and left ventricular outflow tract obstruction. Except for the closure of a patent ductus arteriosus through a lateral thoracotomy in patient \#3, no prior procedures had been performed in this patient cohort.

Symptoms were variable from exertional dyspnea, perspiration, reoccurring respiratory infections and desaturation. Three patients $(33.3 \%)$ were asymptomatic prior to surgery. In one out of these and in two additional patients with symptoms, significant progression of peak gradients measured across the RVOT was the main indication for surgery. More than half (5/9) of the patients were treated with beta-blocker and/or diuretics preoperatively. Mean follow-up of the entire cohort was very short with $1.6 \pm 3.2$ months.

\section{Echocardiographic Diagnosis and Assessment of Flow Disturbances}

At the time of surgery, a large non-restrictive VSD was present in all but one patient (Table 2). Localization was mostly subaortic $(88.9 \% ; 8 / 9)$. Malalignment was present in five patients $(62.5 \% ; 5 / 8)$. Shunt direction was left-to-right in the majority of patients (7/8), with only one patient having significant right-to-left shunting and suffering from cyanosis (patient \#2). The median peak gradient across the VSD was $40 \mathrm{mmHg}$ (IQR 7.3-72.5) and all patients displayed a turbulent high-velocity jet across the RVOTO (Fig. 1). Preoperative median peak flow velocity and peak gradient across the RVOT were $4.2 \mathrm{~m} / \mathrm{s}$ (IQR 1.9-4.7) and $77 \mathrm{mmHg}$ (IQR 55-91.5), respectively. Three patients presented with rapid progression of peak pressure gradients across the RVOT. Patient \#2 showed a peak pressure gradient across the RVOT of $20 \mathrm{mmHg}$ at birth, which gradually increased to $81 \mathrm{mmHg}$ at 4 months of age. It remained at this level until surgery was performed at 8 months of age. Pulmonary valve (PV) morphology and diameter were normal in all patients. Postoperatively, the median measured peak RVOT gradient was $6 \mathrm{mmHg}$ (IQR 4.5-17). No residual VSD was observed at the time of discharge. During short-term follow-up, no reoccurrence of RVOTO was documented in any patient (Table 2).

\section{Histological Analysis of Resected RVOT Tissue}

The resected tissue was localized in the areas depicted in the echocardiographic image and the corresponding sketch in Fig. 1. In all patients, the resected tissue samples contained muscle covered by a thick whitish layer on the endocardial facing surface as seen in Fig. 2A. In the histological analysis of H\&E stainings, the overall texture of the myocardium was maintained but the myocardium was covered by thick layers of tissue with low cell counts (Fig. 2B). In several areas, this surface tissue 


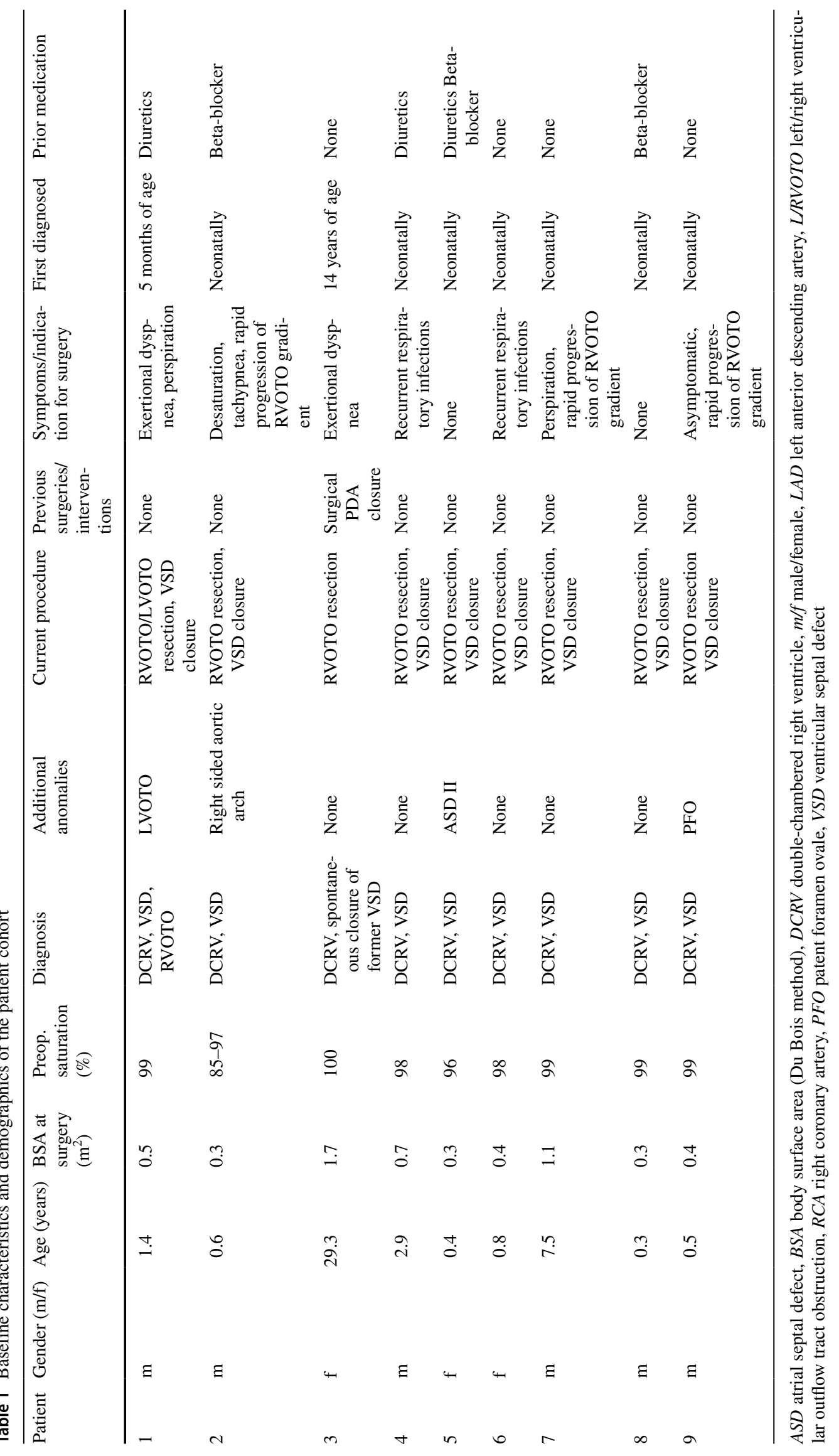


Table 2 Preoperative and postoperative echocardiography of the patient cohort

\begin{tabular}{|c|c|c|c|c|c|c|c|c|}
\hline Patient & $\begin{array}{l}\text { VSD morphol- } \\
\text { ogy }\end{array}$ & $\begin{array}{l}\text { Preop. max. } \\
\text { gradient across } \\
\text { VSD }\end{array}$ & $\begin{array}{l}\text { Shunt direc- } \\
\text { tion across } \\
\text { VSD }\end{array}$ & $\begin{array}{l}\text { Preop. Vmax } \\
\text { across RVOT }\end{array}$ & $\begin{array}{l}\text { Preop. peak } \\
\text { gradient across } \\
\text { RVOTO }\end{array}$ & $\begin{array}{l}\text { Preop. PV } \\
\text { pathology }\end{array}$ & $\begin{array}{l}\text { Postop. peak } \\
\text { gradient across } \\
\text { RVOT }\end{array}$ & $\begin{array}{l}\text { Residual VSD } \\
\text { shunt }\end{array}$ \\
\hline 1 & $\begin{array}{l}\text { Subaortic } \\
(\varnothing 8 \mathrm{~mm}), \\
\text { malalignment }\end{array}$ & 45 & $\mathrm{~L}-\mathrm{R}$ & 1.2 & 77 & None & 12 & None \\
\hline 2 & $\begin{array}{l}\text { Subaortic } \\
(\varnothing 7 \mathrm{~mm}), \\
\text { malalignment }\end{array}$ & 3 & $\mathrm{R}-\mathrm{L}$ & 4.5 & 82 & None & 5 & None \\
\hline 3 & $\begin{array}{l}\text { Subaortic } \\
\text { (almost closed) } \\
\text { no malalignment }\end{array}$ & - & No shunt & 1.2 & 88 & None & 30 & None \\
\hline 4 & $\begin{array}{l}\text { Inlet } \\
(\varnothing 1.5 \mathrm{~cm}, \\
\text { partly covered })\end{array}$ & 75 & $\mathrm{~L}-\mathrm{R}$ & 4.3 & 75 & None & 10 & None \\
\hline 5 & $\begin{array}{l}\text { Subaortic } \\
(\varnothing 8 \mathrm{~mm} \text {, partly } \\
\text { covered) } \\
\text { no malalignment }\end{array}$ & 35 & $\mathrm{~L}-\mathrm{R}$ & 3.3 & 44 & None & 22 & None \\
\hline 6 & $\begin{array}{l}\text { Subaortic } \\
(\varnothing 8 \mathrm{~mm} \text {, partly } \\
\text { covered), } \\
\text { malalignment }\end{array}$ & 65 & $\mathrm{~L}-\mathrm{R}$ & 4.2 & 65 & None & 5 & None \\
\hline 7 & $\begin{array}{l}\text { Subaortic } \\
(\varnothing 3 \mathrm{~mm}), \\
\text { no malalignment }\end{array}$ & 4 & $\mathrm{~L}-\mathrm{R}$ & 4.9 & 95 & None & 3 & None \\
\hline 8 & $\begin{array}{l}\text { Subaortic } \\
(\varnothing 5 \mathrm{~mm}), \\
\text { malalignment }\end{array}$ & 92 & $\mathrm{~L}-\mathrm{R}$ & 2.6 & 45 & None & 4 & None \\
\hline 9 & $\begin{array}{l}\text { Subaortic } \\
(\varnothing 8 \mathrm{~mm}) \text { mala- } \\
\text { lignment }\end{array}$ & 17 & $\mathrm{~L}-\mathrm{R}$ & 4.9 & 97 & None & 6 & $\begin{array}{l}\text { Insignificant } \\
\text { residual } \\
\text { defect }\end{array}$ \\
\hline
\end{tabular}

max. gradient (in $\mathrm{mmHg}$ ) systolic gradient across VSD/RVOT/PV, RVOTO sight ventricular outflow tract obstruction, shunt direction: $L-R / R-L$ left-to-right/right-to-left shunt, postop. postoperative, preop. preoperative, $P R$ pulmonary valve regurgitation, $P V$ pulmonary valve, $V m a x$ maximum flow velocity (in $\mathrm{m} / \mathrm{s})$, VSD ventricular septal defect

showed growth patterns into the underlying myocardium. MT staining was used to identify collagen distribution in these samples. As shown in Fig. 2C, collagen indicated in blue was the predominant component of the thick whitish layer covering the myocardium with infiltration into the underlying myocardium in several areas. Furthermore, collagen and elastin surrounded the myocardial bundles diffusely throughout the myocardium. Subendocardial and intramyocardial collagen was accompanied by elastin. Collagen and elastin appeared in well-organized layers in the subendocardial space (Fig. 2C and D).

As indicated in Fig. 3, all patients showed areas of double-stained cells (CD31/ $\alpha$-SMA) within the subendocardial layers but also within the areas which grew infiltratively into the underlying myocardium indicative for EndMT. The presence of active EndMT was confirmed by co-localization of stained endothelial cell nuclei with the transcription factors Slug/Snail (Fig. 3B). In all patients, subendocardial EndMT with connected areas of myocardial infiltrations were identified. In a single patient, capillary EndMT within the myocardium was also present (Fig. 3C).

The degree of myocardial hypertrophy was not significantly different $(P=0.08)$ between DCRV samples and nonhypertrophied control samples (Fig. 4A and B).

\section{Discussion}

In this study we set out to determine the remodeling process and associated triggers for the septation within the RV creating two different pressured chambers, better known as DCRV. All patients presented with flow disturbances across abnormal muscle bundles associated with the obstruction of the RVOT and across the VSD. Histological analysis of the tissue resected from the RVOTO during DCRV correction revealed that hypertrophy of the myocardium was not the only component of the formation of this septation, but the resected tissue resembled fibroelastic tissue with distinct 

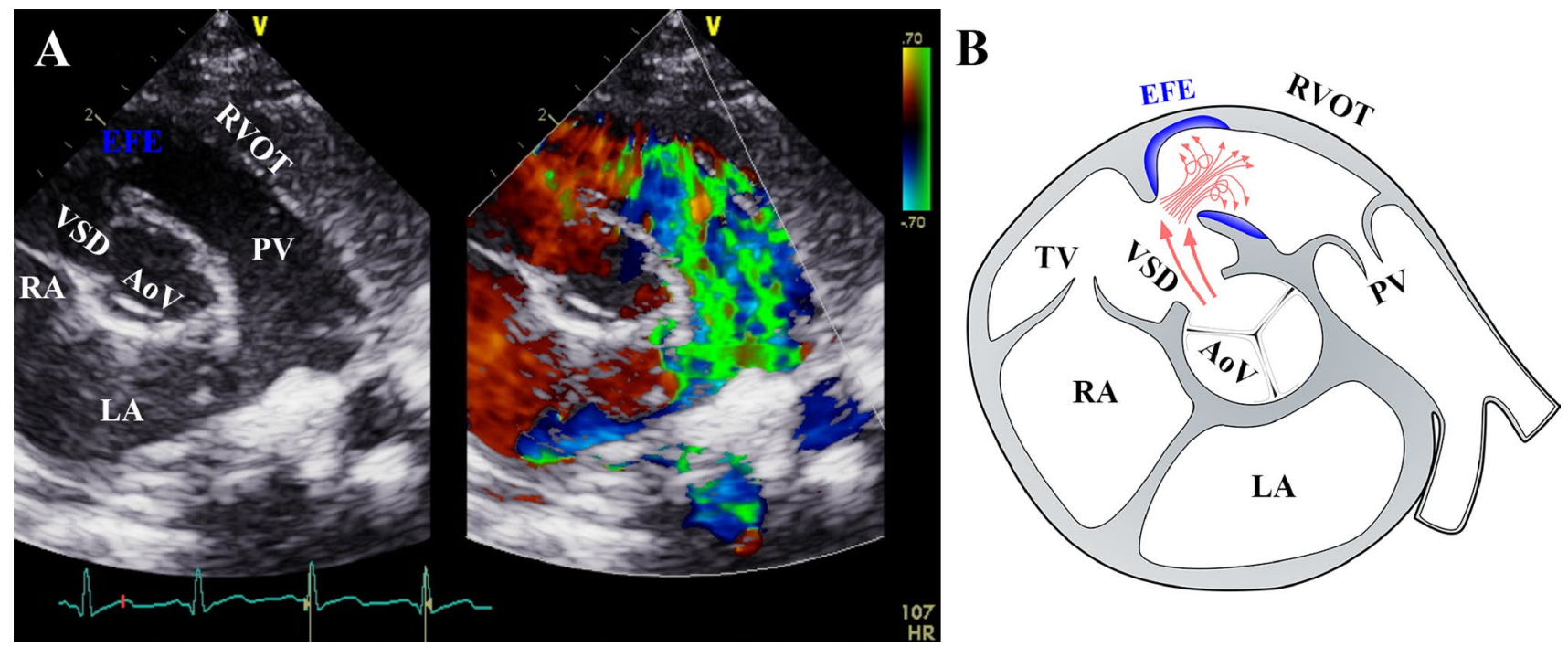

Fig. 1 A Representative preoperative color-Doppler echocardiogram from a parasternal short-axis view. Diagnosis of DCRV is established via identification of key components (double-chambered RVOTO and VSD with significant flow disturbances) by echocardiography. A representative image is provided. B Sketch of $(\mathbf{A})$ : The associated graph- ical display of the DCRV pathology indicates the flow turbulence across the anomalous muscle bundles and the associated high-velocity turbulent flow jet. $E F E$ endocardial fibroelastosis, VSD ventricular septal defect, $R V O T$ right ventricular outflow tract, $P V$ pulmonary valve, $A o V$ aortic valve, $L A$ left atrium, $R A$ right atrium
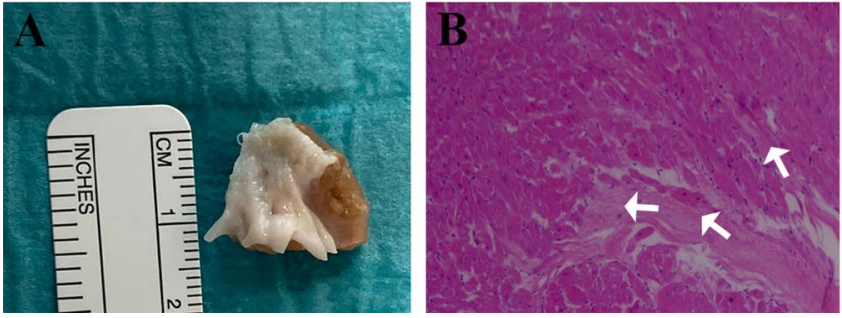

Fig. 2 A representative RV tissue sample is shown which is comprised of muscle and fibrotic tissue (A). Histological analysis was performed through staining with hematoxylin and eosin (B) for assessment of overall tissue texture; with Masson's Trichrome $(\mathbf{C})$ for

layering of collagen and elastic fibers with infiltrative growth into the underlying myocardium. This fibroelastic tissue developed through localized activation of EndMT which was confirmed through immunohistochemical double-staining of endothelial cells by endothelial (CD31) and mesenchymal markers ( $\alpha$-SMA) and by activation of EndMT modulating transcription factors Slug/Snail. EndMT was, however, only associated with the endocardial endothelial cell layer but did not affect the capillary endothelial cells within the myocardium, except a few EndMT positive endothelial cells in the subendocardial myocardium in one patient, which is typically associated with myocardial hypertrophy as we have previously shown $[12,13]$. Thus, DCRV is not only a result of hypertrophying muscle bundles but also due to an invasive remodeling process of the endocardium and underlying myocardium due to activation of EndMT.
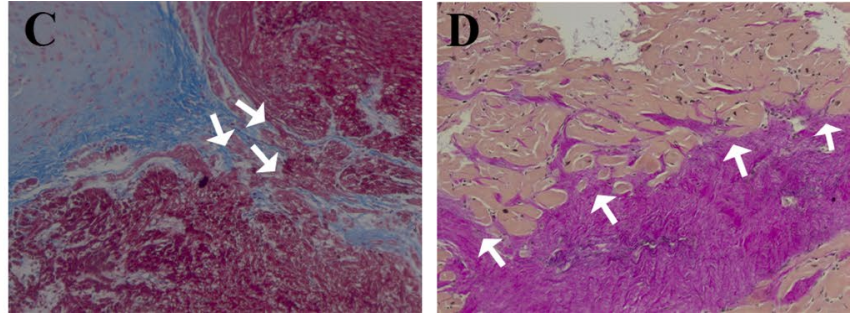

determination of fibrosis and Van Giesson (D) staining for visualization of elastin content. Collagen and elastin are prominently displayed subendocardially in organized layers and are also found infiltrating into the underlying myocardium (white arrows)

Diagnosis of DCVR was performed by echocardiography in all cases. The presence of a clear septation within the RV into two separate chambers and a gradient across the outflow tract with significant turbulence without involvement of the pulmonary valve served as the basis to distinguish DCRV from Tetralogy of Fallot. Shortness of breath and exercise intolerance such as dyspnea on exertion have been described as the most common clinical symptoms which we confirmed in our patient cohort as well $[14,15]$. Unless treated surgically, DCRV is a progressive disease with gradually increasing severity of the obstruction through the septation within the RVOT. Surgery is generally performed during childhood. Due to late referral of some out-of-the country patients, our patient cohort also included an adult patient which provides an interesting window into the natural progression of 


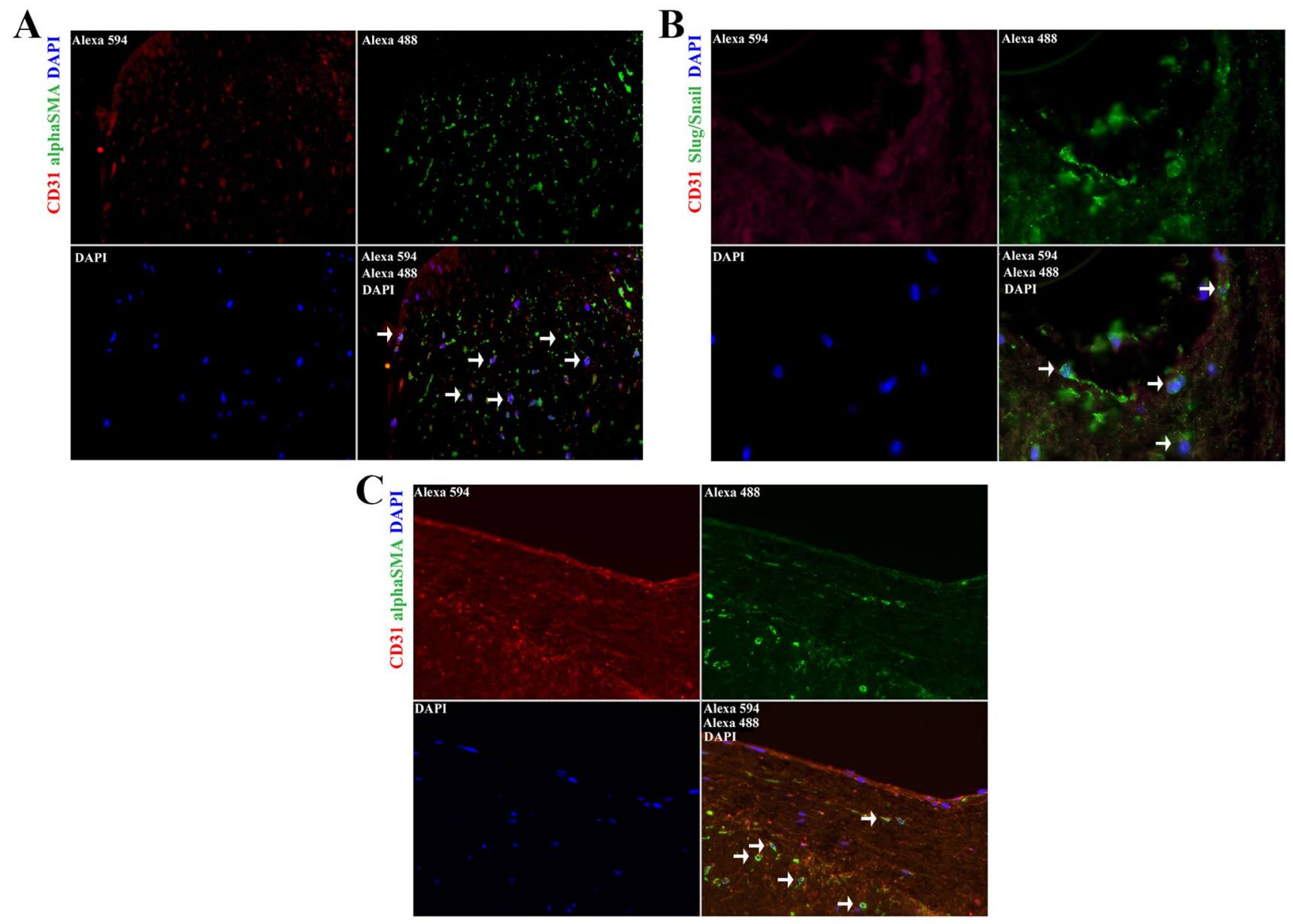

Fig. 3 A Representative immunohistochemical stainings are shown. EndMT was verified by double-staining of endocardial endothelial cells with CD31 (in red) and $\alpha$ SMA (in green). Yellow colored cells are indicative of active EndMT as pointed out by white arrows. Nuclei appear in blue. As indicated, layers on top of the myocardium as well as areas of infiltrative growth into the myocardium are positive for EndMT (see white arrows) but the underlying myocardium is

the disease. Most patients present with typical symptoms but the degree of incapacitation is highly variable which is associated with the wide range in severity of the RV obstruction. Especially older patients had only mild symptoms despite significant gradients across the RV which is in accordance with a study by Kahr et al. [4]. Rapid progression of the RVOT obstruction with increasing gradients, was the primary cause for referral in these patients. In the remaining patients of our cohort, indications for surgical correction were respiratory symptoms, indicative of worsening gradients across the RVOT. Resection of the obstructive lesion through surgery is the treatment of choice for symptomatic patients and/or patients with gradients greater than $40 \mathrm{mmHg}$ [2]. Following successful resection to remove the RVOTO, long-term outcome is excellent. Re-operation for recurrent RVOTO was not free from EndMT, except for one patient where the subendocardial myocardium shows a small number of EndMT positive endothelial cells. B Nuclei in CD31 positive cells double-stained for Slug/Snail are indicative of active EndMT (white arrows). CD31 is shown in red, nuclei stained with DAPI in blue and Slug/Snail in green. C Intramyocardial EndMT through double-staining of CD31 and $\alpha$ SMA (white arrow) as identified in one patient

necessary during a median follow-up of 8 years according to a previous study [4]. Long-term follow-up for our patient cohort is not yet available but repair of the underlying cause for flow turbulence may prevent localized remodeling through EndMT.

There is no consensus on the pathogenetic components that result in the development of DCRV. Hypertrophy of accessory or abnormal septo-parietal trabeculations associated with the moderator band have long been discussed as the underlying cause of DCRV formation [16]. However, Alva et al. characterized DCRV as a primary infundibular stenosis with obstructive fibrous muscle bands at the junction of the main RV cavity and the proximal infundibulum [17]. Muscle bundles as substrate for DCRV are potentially present at birth already but develop into an obstruction progressively over time due to localized alterations [18]. The 
A

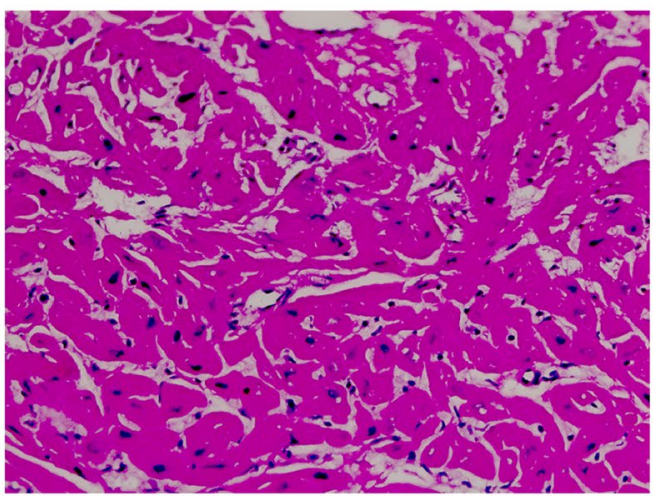

Non-hypertrophied control

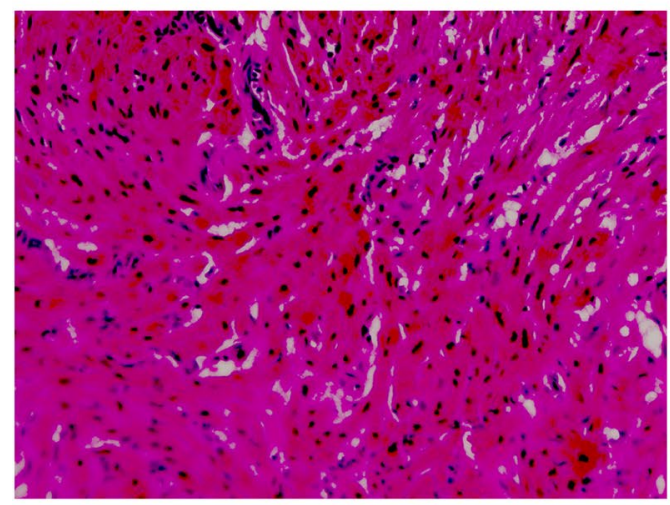

DCRV tissue

Fig. 4 A Myocardial hypertrophy was determined by comparing the ratio of myocardium to number of nuclei per field of vision between DCRV tissue and non-hypertrophied human histological sections. B

results of our study implicate active EndMT with remodeling of the endocardium and subendocardial myocardium as a potential cause of such progressive obstruction.

As described by Nikolic et al., DCRV progression is associated with left-to-right shunting through a VSD which creates a jet directed toward the RV-free wall or crista supraventricularis, suggesting that flow turbulences might be associated with progressive obstruction [19]. In the majority of reported cases, a VSD is present which was also true for our patient population. In accordance with a report by Hubail et al., a subaortic VSD communicating with the proximal low-pressure chamber was the predominant defect. The reported intracavitary pressure difference of $67 \mathrm{mmHg}$ to $83 \mathrm{mmHg}$ within the $\mathrm{RV}$ was also similar to our findings [20].

As indicated by our data, myocardial hypertrophy of the anomalous muscle bundles projecting into the RV and obstructing blood flow within the RVOT is likely not the only element of progressive obstruction and DCRV
B

\section{Degree of myocardial hypertrophy}

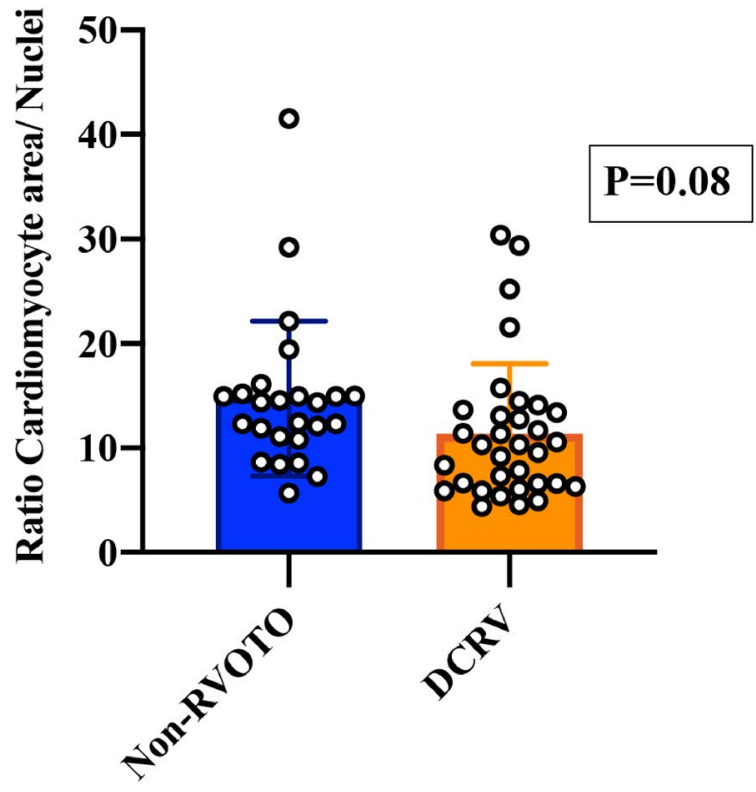

Summary statistics shows that there was no difference in the myocardial area/number nuclei ratio between the two groups. Data are expressed as mean $\pm \mathrm{SD}$

formation. In fact, we documented fibrotic and elastic alteration of the septation similar to endocardial fibroelastosis. Organized layers of collagen and elastin as we have previously described in EFE tissue obtained from left ventricular diseases were predominantly present in these tissue samples $[8,9]$. Furthermore, the fibrotic remodeling process infiltrated into the underlying myocardium which we have also seen in disease progression on the left side of the heart $[8$, 9]. The location of the VSD directly influences the hemodynamic profile since the VSD potentially stimulate localized remodeling which further aggravates the progression of the obstruction in the affected area and in turn results in additional high-velocity flow turbulences. The latter then trigger localized changes and stimulate cellular events such as EndMT of the endocardium leading to fibrotic remodeling of the outflow tract. These findings are similar to our previously published observations where flow turbulences with jets across stenotic valves on LV resulted in endocardial fibroelastosis formation. As indicated in Fig. 1, a high-powered 
jet and flow turbulences are visible which targets the area of the septation causing DCRV. Similar findings of jets and flow turbulences were described in an MRI study by Ibrahim et al. [21]. Rapid progression of the intraventricular gradient has been reported to result from a combination of increased localized myocardial hypertrophy and fibrosis. However, our study now established for the first time that this fibrotic process is the result of localized remodeling due to EndMT of the endocardium and may play a key role in the progression toward a DCRV [1]. Due to the small sample size, any conclusion regarding age differences in disease progression or degree of hypertrophy is not possible and has to be addressed in follow-up studies.

In conclusion, the initial septation of the RV is most likely due to abnormal muscle bundles as it has been widely discussed [20]. However, our results indicate that the ultimate progressive septation is a consequence of EndMTinduced fibrosis most likely triggered by flow disturbances imposed on the RVOT by blood flow turbulences caused by abnormal muscle bundles and across the VSD. Our current findings establish an interesting association which requires further research to establish a clear causal relationship and the tempo-spatial patterns of events leading to DCRV formation which may allow for early non-surgical intervention.

Acknowledgements The study was approved by the Ethics Committee Charité-Universitätsmedizin Berlin (Protocol Number of IRB Approval: EA2/152/19).

Funding The study was supported by internal funding.

\section{Declarations}

Conflict of interest The authors declare that they have no conflict of interest.

Open Access This article is licensed under a Creative Commons Attribution 4.0 International License, which permits use, sharing, adaptation, distribution and reproduction in any medium or format, as long as you give appropriate credit to the original author(s) and the source, provide a link to the Creative Commons licence, and indicate if changes were made. The images or other third party material in this article are included in the article's Creative Commons licence, unless indicated otherwise in a credit line to the material. If material is not included in the article's Creative Commons licence and your intended use is not permitted by statutory regulation or exceeds the permitted use, you will need to obtain permission directly from the copyright holder. To view a copy of this licence, visit http://creativecommons.org/licenses/by/4.0/.

\section{References}

1. Forster JW, Humphries JO (1971) Right Ventricular anomalous muscle bundle: clinical and laboratory presentation and natural history. Circulation 43(1):115-127. https://doi.org/10.1161/01.cir. 43.1.115
2. McElhinney DB, Chatterjee KM, Reddy VM (2000) Doublechambered right ventricle presenting in adulthood. Ann Thorac Surg 70(1):124-127. https://doi.org/10.1016/s0003-4975(00) 01320-5

3. Peacock TB (1858) On malformations of the human heart, vol 60. John Churchill and Sons, London

4. Kahr PC, Alonso-Gonzalez R, Kempny A, Orwat S, Uebing A, Dimopoulos K et al (2014) Long-term natural history and postoperative outcome of double-chambered right ventricle-experience from two tertiary adult congenital heart centers and review of the literature. Int J Cardiol 174(3):662-668. https://doi.org/10.1016/j. ijcard.2014.04.177

5. Hindle WV, Engle MA, Hagstrom JWC (1968) Anomalous right ventricular muscles: a clinicopathologic study. Am J Cardiol 21(4):487-495. https://doi.org/10.1016/0002-9149(68)90280-4

6. Maron BJ, Ferrans VJ, White RI (1973) Unusual evolution of acquired infundibular stenosis in patients with ventricular septal defect: clinical and morphologic observations. Circulation 48(5):1092-1103. https://doi.org/10.1161/01.cir.48.5.1092

7. Matina D, van Doesburg NH, Fouron JC, Guérin R, Davignon A (1983) Subxiphoid two-dimensional echocardiographic diagnosis of double-chambered right ventricle. Circulation 67(4):885888. https://doi.org/10.1161/01.cir.67.4.885

8. Weixler V, Marx GR, Hammer PE, Emani SM, del Nido PJ, Friehs I (2020) Flow disturbances and the development of endocardial fibroelastosis. J Thorac Cardiovasc Surg 159(2):637-646. https://doi.org/10.1016/j.jtcvs.2019.08.101

9. Weixler V, Hammer PE, Marx GR, Emani SM, del Nido PJ, Friehs I (2019) Flow disturbances and progression of endocardial fibroelastosis - a case report. Cardiovasc Pathol 42:1-3. https://doi.org/10.1016/j.carpath.2019.04.004

10. Oh N, Hong X, Doulamis IP, Meibalah E, Peiseler T, MeleroMartin JM, Garcia-Cardena G, del Nido PJ, Friehs I (2021) Abnormal flow conditions promote endocardial fibroelastosis via endothelial-to-mesenchymal transition, which is responsive to Losartan therapy. JACC: Basic Transl Sci 6(12):984-999. https://doi.org/10.1016/j.jabts.2021.10.002

11. Xu X, Friehs I, Zhong HuT, Melnychenko I, Tampe B, Alnour $F$ et al (2015) Endocardial fibroelastosis is caused by aberrant endothelial to mesenchymal transition. Circ Res 116(5):857866. https://doi.org/10.1161/CIRCRESAHA.116.305629

12. Illigens BM-W, Casar Berazaluce A, Poutias D, Gasser R, del Nido PJ, Friehs I (2017) Vascular endothelial growth factor prevents endothelial-to-mesenchymal transition in hypertrophy. Ann Thorac Surg 104(3):932-939. https://doi.org/10.1016/j. athoracsur.2017.01.112

13. Zeisberg EM, Tarnavski O, Zeisberg M, Dorfman AL, McMullen JR, Gustafsson E et al (2007) Endothelial-to-mesenchymal transition contributes to cardiac fibrosis. Nat Med 13(8):952961. https://doi.org/10.1038/nm1613

14. Singh JP, Evans JC, Levy D, Larson MG, Freed LA, Fuller DL et al (1999) Prevalence and clinical determinants of mitral, tricuspid, and aortic regurgitation (the Framingham Heart Study). Am J Cardiol 83(6):897-902. https://doi.org/10.1016/s00029149(98)01064-9

15. Telagh R, Alexi-Meskishvili V, Hetzer R, Lange PE, Berger F, Abdul-Khaliq H (2008) Initial clinical manifestations and midand long-term results after surgical repair of double-chambered right ventricle in children and adults. Cardiol Young 18(3):268274. https://doi.org/10.1017/S1047951108001984

16. Wong PC, Sanders SP, Jonas RA, Colan SD, Parness IA, Geva T et al (1991) Pulmonary valve-moderator band distance and association with development of double-chambered right ventricle. Am J Cardiol 68(17):1681-1686. https://doi.org/10.1016/ 0002-9149(91)90329-j 
17. Alva C, Ho SY, Lincoln CR, Rigby ML, Wright A, Anderson RH (1999) The nature of the obstructive muscular bundles in double-chambered right ventricle. J Thorac Cardiovasc Surg 117(6):1180-1189. https://doi.org/10.1016/s0022-5223(99) 70258-8

18. Hartmann AF, Goldring D, Carlsson E (1964) Development of right ventricular obstruction by aberrant muscular bands. Circulation 30(5):679-685. https://doi.org/10.1161/01.cir.30.5. 679

19. Nikolic A, Jovovic L, Ilisic T, Antonic Z (2016) An (in)significant ventricular septal defect and/or double-chambered right ventricle: are there any differences in diagnosis and prognosis in adult patients? Cardiology 134(3):375-380. https://doi.org/10.1159/ 000444743
20. Hubail ZJ, Ramaciotti C (2007) Spatial relationship between the ventricular septal defect and the anomalous muscle bundle in a double-chambered right ventricle. Congenit Heart Dis 2(6):421423. https://doi.org/10.1111/j.1747-0803.2007.00135.x

21. Ibrahim T, Dennig K, Schwaiger M, Schömig A (2002) Assessment of double chamber right ventricle by magnetic resonance imaging. Circulation 105(22):2692-2693. https://doi.org/10.1161/ 01.cir.0000013206.40857.b6

Publisher's Note Springer Nature remains neutral with regard to jurisdictional claims in published maps and institutional affiliations. 